\title{
Performance of epoxy-nanocomposite under corrosive environment
}

\author{
N. Abacha*, M. Kubouchi, K. Tsuda, T. Sakai \\ Tsuda \& Kubouchi Laboratory, Department of Chemical Engineering, Tokyo Institute of Technology, 2-12-1-S1-17 \\ O-okayama, Meguro-ku, Tokyo 152-8552, Japan
}

Received 17 March 2007; accepted in revised form 9 May 2007

\begin{abstract}
Nanocomposite materials consisting of polymeric matrix materials and natural or synthetic layered minerals like clay are currently an expanding field of study because these new materials often exhibit a wide range of improved properties over their unmodified starting polymers. Epoxy/organoclay nanocomposites have been prepared by intercalating epoxy into the organoclay via direct mixing process. The clay exfoliation was monitored by X-ray diffraction (XRD) and transmission electron microscopy (TEM). Water diffusion and sulfuric acid corrosion resistance of epoxy-based nanocomposites were evaluated. Diffusion was studied through epoxy samples containing up to $6 \mathrm{phr}$ (parts per hundred resin) of an organically treated montmorillonite. The diffusion of the environmental solution was measured by noting the increase in weight of the samples as a function of immersion time in these solutions at $80^{\circ} \mathrm{C}$. The effect of the degree of exfoliation of the organoclay on water barrier and corrosion resistance was specifically studied. The data have been compared to those obtained from the neat epoxy resin to evaluate the diffusion properties of the nanocomposites. The flexural strength of the epoxy/organoclay nanocomposites samples made was examined to compare their mechanical performance under corrosive conditions as a function of immersion time and temperature. It was found, that the organoclay was mainly intercalated with some exfoliation and that addition of the organoclay yields better flexural strength retention under immersion into sulfuric acid.
\end{abstract}

Keywords: thermosetting resins, diffusion, nanocomposite, acid aging

\section{Introduction}

The research on polymer-layered silicate nanocomposites is currently an expanding field of investigation, this is mainly due to the large potential to achieve property enhancement significantly greater than that attainable using conventional fillers or polymers blends [1-3].

Understanding and controlling the various factors that govern the making of exfoliated thermoset/layered silicate nanocomposite is rather complex, several research projects have focused and made contribution to understand some of these issues [4-6]. Nanocomposites have the ability and the potential to reduce the permeability of polymer

*Corresponding author, e-mail: abacha@ @ chemeng.titech.ac.jp

(C) BME-PT and GTE composites against ingress of corrosive substances. The reduction in permeability that can be attained from the exfoliation of layered silicates into polymers depends on the permeating agent being investigated. Few studies have been carried up to now on the effect of moisture on the barrier properties of nanocomposites [7-9], although very limited studies have treated the corrosive environment on the nanocomposites.

Epoxy based thermosetting polymer resins are widely used in the industry due to their superior characteristics such as good mechanical properties, and good resistance to chemicals. Significant use of epoxy resins as the matrix material in fiber reinforced composites, for the application in the aero- 
space and automotive industry [10-12]. However, such composites are highly susceptible to environmental conditions, primarily due to the degradation of epoxy matrix $[8,10,11]$.

In our laboratory, epoxy/layered silicate nanocomposite has been developed, and the effects on the morphology development and properties have been investigated. The characterization of the environmental degradation (immersion in water or in sulfuric acid) under temperature of $80^{\circ} \mathrm{C}$ was focused on. It is expected that the addition of organoclay could increase the life service time by offering a barrier to water/ acid transportation.

\section{Experiments}

\subsection{Materials and sample preparation}

Bisphenol A type Epoxy Epomik R140 from Mitsui Chemical Co., Ltd was used as the matrix; Jeffamine D230 a diamine curing agent from Huntsman Co., and the organoclays used was the Nanomer I.28E from Nanocor Inc.

The organoclay was swelled with the curing agent and mixed with a mechanical stirrer at $1500 \mathrm{rpm}$ for $1 \mathrm{~h}$ at $60^{\circ} \mathrm{C}$, followed by ultra-sonication for an additional $1 \mathrm{~h}$. After this, epoxy resin was added. Prior to curing, a degassing under vacuum was applied. Curing was done in two stages first at $70^{\circ} \mathrm{C}$ for $6 \mathrm{~h}$ followed by a post cure at $110^{\circ} \mathrm{C}$ for an additional $6 \mathrm{~h}$. The load of the clay was varied from 0.5 to $6 \mathrm{phr}$ (parts per hundred resin).

\subsection{Characterization}

X-Ray diffraction (XRD) was performed on a Philips Xpert MPD PW3050 X-ray diffractometer with a $\mathrm{CuK} \alpha$ as a radiation source $(\lambda=1.54)$, operated at $40 \mathrm{kV}$ and $30 \mathrm{~mA}$. Samples were scanned at diffraction angles $\left(2 \theta^{\prime} \mathrm{s}\right)$ from $2^{\circ}$ to $10^{\circ}$ at a scan speed of $0.016 \%$ s.

Transmission Electron microscope (TEM) photographs were taken with a JEOL JEM 2010F using an acceleration voltage of $200 \mathrm{kV}$.

The penetration depth of the sulfur (S) element was monitored using the coupled Scanning Electron Microscopy (SEM)/Energy dispersive X-ray spectrometer (EDS) JEOL JSM-5310LV analysis of the cross section of the immersed samples in sulfuric acid. Bending test was done according to ASTM D790 with Shimadzu Autograph AGS-1KNJ machine.

\subsection{Measurement of weight change}

The mass uptake of samples having dimension $60 \times 25 \times 2 \mathrm{~mm}$ immersed in deionized water and 10 mass \% sulfuric acid medium separately at $80^{\circ} \mathrm{C}$ using constant temperature bath, was measured by recording the amount of the solution absorbed within a fixed interval of immersion time.

Before immersion all samples were dried at $60^{\circ} \mathrm{C}$ for $50 \mathrm{~h}$ and their initial weights and dimensions were measured. The specimens were periodically removed, wiped with filter paper to remove excess solution, and then were kept for $1 \mathrm{~h}$ at room temperature before their weights - wet condition - were taken. Solution content was determined using Equation (1):

$M_{t}[\%]=\frac{W_{t}-W_{0}}{W_{0}} \cdot 100$

where $M_{t}, W_{t}$ and $W_{0}$ are the solution content at a given time, weight of the sample at the time of the measurement and initial weight, respectively.

\section{Results and discussion}

\subsection{Nanocomposite morphology}

Figure 1 illustrates the XRD spectrum of the pristine organoclay and that of the epoxy/organoclay nanocomposite with different clay content. The basal spacing of the pristine organoclay was about $24.18 \AA$ presented as a single peak around $2 \theta=3.65^{\circ}$. This peak was shifted to lower value when mixed with the epoxy to form the nanocomposite materials. This was an indication that epoxy

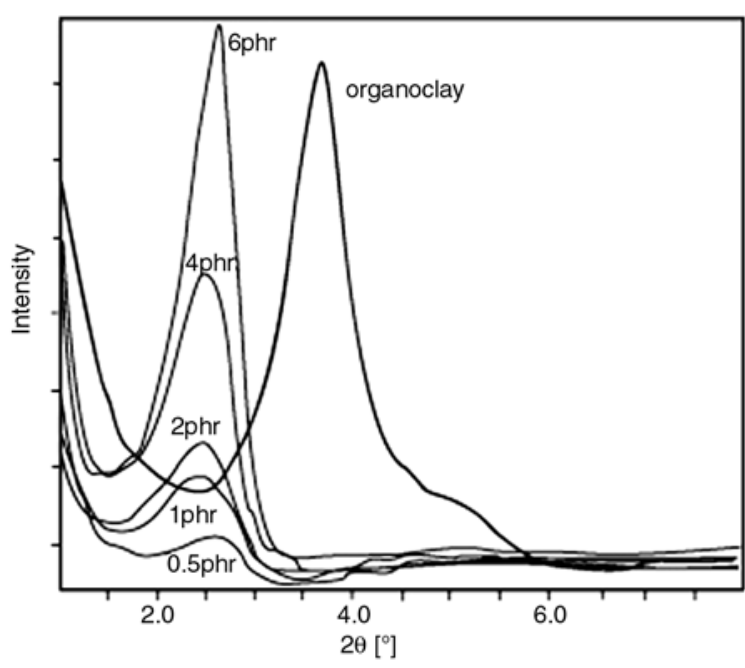

Figure 1. XRD spectrum of the different formulations 
was intercalated between the layers of clay during mixing, which eventually expands or exfoliates the clay layers; the d-spacing was shifted from the original value of $24.18 \AA$ to that around $34 \AA$.

By XRD, the formed nanocomposite simply would be defined as intercalated, in that there was an observed increase in the d-spacing as compared to the original clay d-spacing.

It also is observed that the higher the clay contents the higher the peak area. This is attributed to the high concentration of the organoclay that may agglomerate within the matrix and thus become difficult to disperse and to exfoliate within epoxy resin.

TEM images of the sample containing 1 phr organoclay are shown in Figures $2 a$ and $2 b$, where the dark lines are the cross section of silicate, it reveals that although there were intercalated multilayer crystalline present, single exfoliated silicate layers were also prevalent. At low TEM magnification Figure 2a micrograph showed that the clay was well dispersed throughout the polymer with some agglomeration. Higher magnification (Figure 2b) showed that regions where both intercalated and exfoliated structures existed and regions were both intercalated tactoids and a few individual layers were present. Hence, the designation of an intercalated/exfoliated type of nanocomposite is recognized as already noted in XRD analysis.

This to conclude that achieving a full exfoliation with this material is quite difficult, and to reach an optimum one must try different ways and combinations of mixing.

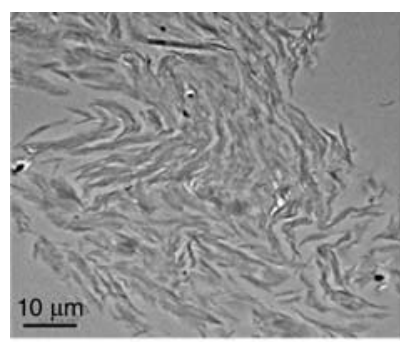

a)

Figure 2. TEM micrograph of 1phr epoxy/organoclay nanocomposite at different magnification: a) low magnification, b) high magnification

\subsection{Diffusion test}

Materials (neat epoxy or epoxy/organoclay nanocomposite) immersed into water or into sulfuric acid at $80^{\circ} \mathrm{C}$, gained mass due to the environmental solution uptake, as shown in Figures 3 and 4 for water and sulfuric acid respectively. The weight gain $\left(M_{t}\right)$ over the equilibrium weight gain $\left(M_{\infty}\right)$ as a function of root time per specimen thickness $\left(t^{1 / 2} / l\right)$; increased approximately linearly before saturation occurred.

The equilibrium mass uptake for neat epoxy was around 3\% for immersion in water and around 18\% for immersion in sulfuric acid. Obviously the mass uptake in acid is much higher than that in water due to the formation of a tertiary amine salt amine group [13], when all the amines in the resin are converted to amine salt, the weight gain reaches the equilibrium level [14].

In the case of water diffusion, no real performance of the added organoclay was found and similar trend is obtained as illustrated in Figure 3 the equilibrium mass uptake remains within the same value as for neat epoxy. It was expected that the incorporation of the organoclay increases the tortuosity path and thus decreases the equilibrium mass uptake, however, this was not the case, this may be explained by the fact that the organoclay was not fully exfoliated, and was rather intercalated with some agglomeration. Another important factor that could play an important role is that the organoclay may have kept some of its naturally hydrophilic characteristic and thus still attract water. Finally the presence of micro voids due to the increase in viscosity when mixing the organoclay. The free pore volume can easily take up the solvent molecules and increases the mass uptake.

Some authors find similar trend as in the case of Lan and Pinnavaia [3], Massam and Pinnavaia [15] and Becker et al. [12] where they found in their

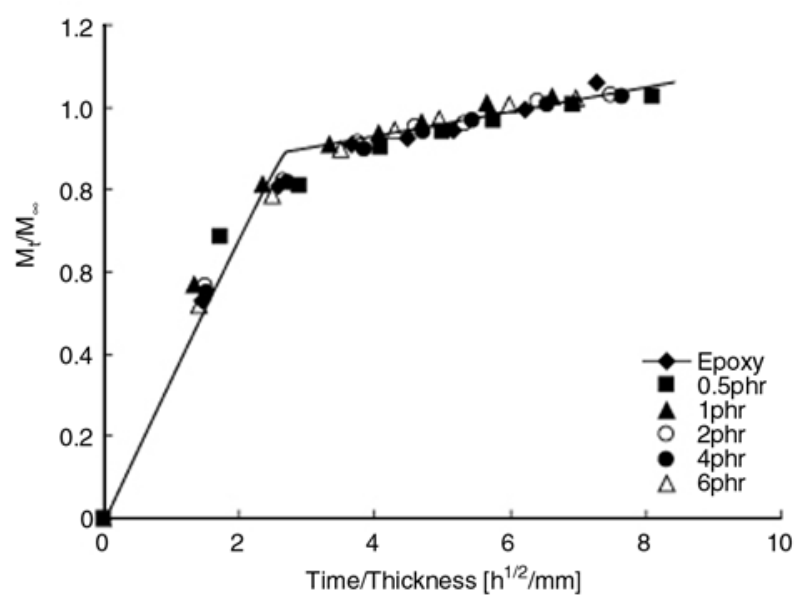

Figure 3. Weight gain in water as function of immersion square root time 


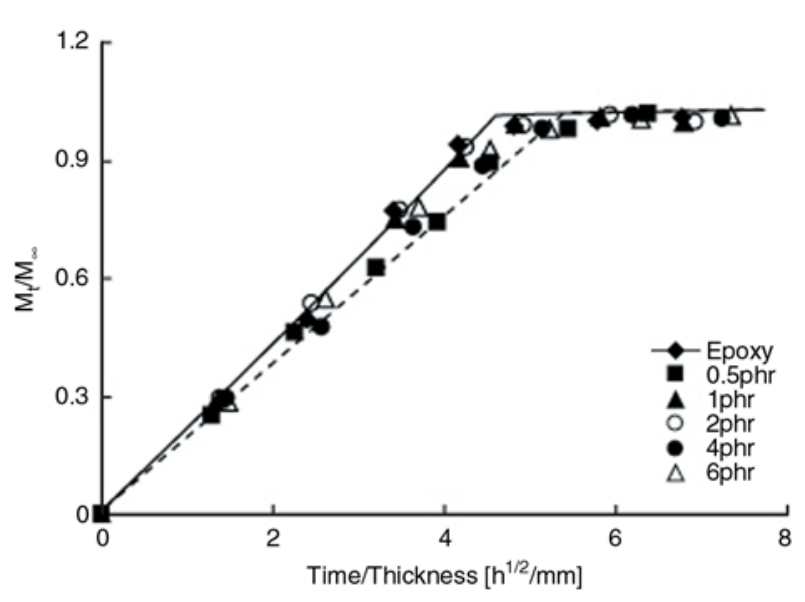

Figure 4. Weight gain in sulfuric acid as function of immersion square root time

studies concerning epoxy nanocomposite performance towards water and other organic solvent; that only the rate of absorption was reduced, and that the equilibrium water uptake was found to be relatively higher in the case of epoxy clay nanocomposite. The equilibrium moisture uptake was found to increase with the amount of layered silicate added.

It is suggested a dual effect between the benefit of adding high aspect ratio filler as a barrier properties enhancement to the above cited counter performance reasons i. e. not fully exfoliated, agglomeration, voids... etc.

On the other hand, for the case of acid uptake, a similar tendency was also obtained for neat epoxy and epoxy organoclay nanocomposite that is a linear increase as function of square root immersion time; however, lower values were obtained for the organoclay content of $0.5 \mathrm{phr}$ as observed in Figure 4. At low organoclay content, better barrier properties performance was obtained, for the reason that the degree of exfoliation is higher with better dispersion and no agglomeration, it estimated that the tortuous path model appear to hold well only at very low clay loadings $(<1 \mathrm{wt} \%)$ with significant deviations at higher loadings ( 1 to $5 \mathrm{wt} \%$ ) and with change in humidity and temperature [16]. Acids diffuse quite easily into amine cured epoxy resin. The reaction between the resin and the penetrating acid cannot be excluded as already explained. The acid corrosivities are dependent rather on the chemical reaction running between the acid and the epoxy chain. These chemical reactions run in parallel with a purely physical diffusion processes.
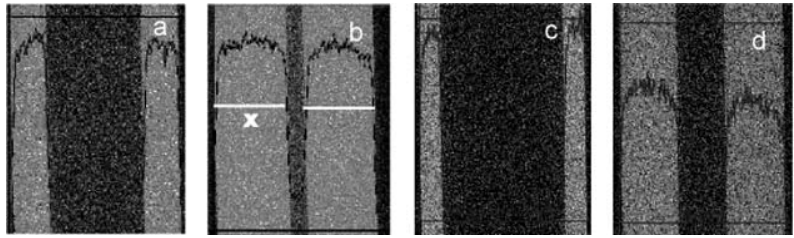

Figure 5. Example of EDS micrograph for S element detection at different immersion time: a) epoxy at $8 \mathrm{~h}$, b) epoxy at $50 \mathrm{~h}, \mathrm{c}) 0.5 \mathrm{phr}$ at $8 \mathrm{~h}$ and d) $0.5 \mathrm{phr}$ at $50 \mathrm{~h}$

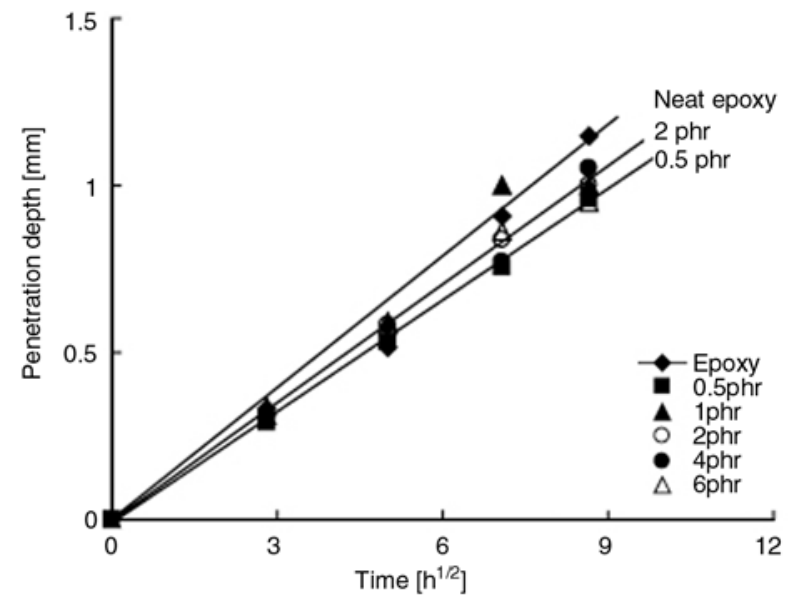

Figure 6. Sulfuric acid penetration depth as function of square root immersion time

To confirm the penetration of sulfur, observation with SEM/EDS was performed, it enabled to measure the penetration depth of the sulfuric acid by detection of the element S. Typical curves of the EDS micrographs are illustrated in Figure 5 where the dark line expresses the profile of the element $S$ along to depth from surface, the penetration depth was calculated to be the distance from surface to level off the profile ( $x$ in Figure 5b).

Figure 6 shows the penetration depth as function of square root time, it is clearly observed the decrease of the penetration depth as organoclay was added to the epoxy system, the marked decrease was obtained as expected with $0.5 \mathrm{phr}$, however, all samples were fully penetrated within a short time around 120 hours which is considered too fast for protecting or coating application.

\subsection{Mechanical properties}

Three point bending test was performed for specimen under wet conditions, an average of three test samples were taken. Figure 7 illustrates the flexural strength of the initial value of the nanocomposite as function of the organoclay content. Flexural strength was relatively decreased as compared to 


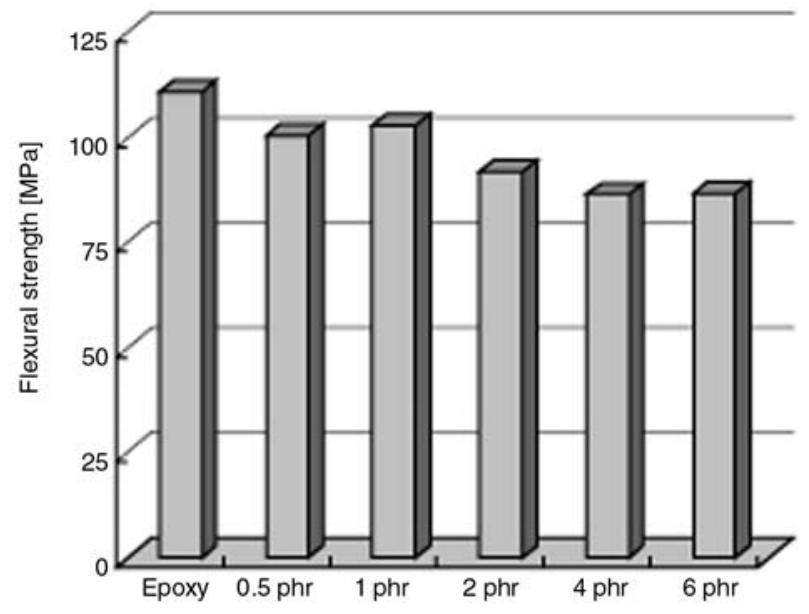

Figure 7. Flexural strength of the different formulation

the neat epoxy resin, this may be a result of the agglomeration effect of the organoclay within the epoxy matrix; making the distribution of the particles in the matrix an important factor to be considered in this case. It is known that the stress distribution around the particles increases the stress concentration of the propagating crack, which in turn induces relative early failure. The important parameter that affects this property is the quality of the interface in the composite that is the adhesive strength and the interfacial stiffness of the composite medium. These two factors play a crucial role in stress transfer and the elastic deformation from the matrix to the fillers [17].

The retention of the flexural strength as function of the immersion time is illustrated in the Figures 8 and 9 for water and acid respectively in wet condition, a decrease followed by a level off is observed as function of immersion time. This decrease is more expressed for the neat epoxy than in the case of the epoxy-clay nanocomposite. When organ-

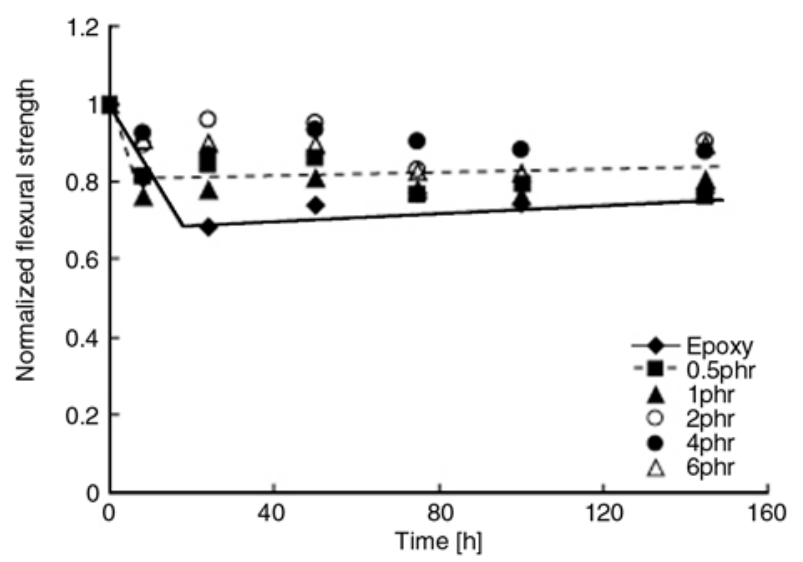

Figure 8. Normalized flexural strength of specimen immersed in water (wet condition)

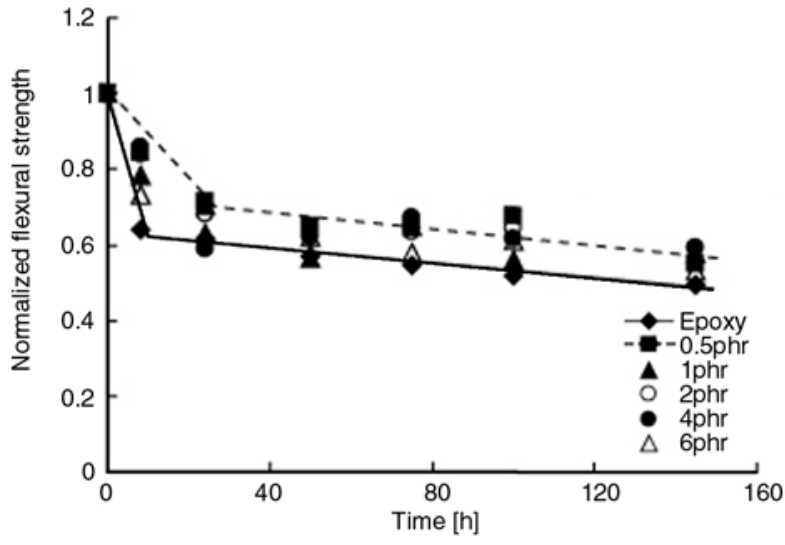

Figure 9. Normalized flexural strength of specimen immersed in sulfuric acid (wet condition)

oclay was added the percent decrease of both modulus and flexural strength is more retained. The decrease is mainly due to the formation as already discussed of the tertiary ammonium salt consequently sever distortion is produced around the amine salt and the stability of the $\mathrm{C}-\mathrm{N}$ bond decreases, causing the scission of the bonds and the decrease in the strength [14], however, when the organoclay is added, this distortion may be obstructed by its presence, even though deeper analysis of the chemical reaction that might occur must be performed.

\section{Conclusions}

A number of observations and conclusions can be drawn from this investigation:

The materials prepared were found to have inhomogeneous degree of exfoliation with rather high degree of intercalation. Under the present processing conditions, the additions of the organoclay can significantly improve the barrier properties against corrosive acid. When immersed in water the absorption parameter seems to be unaffected by the presence of the clay, this seems to be related to the fact that results of sorption are not very sensitive to the extent of filler exfoliation when the diffusing media i. e. water is strongly absorbed by the filler surface. Addition of clay leads to better mechanical properties at wet conditions.

\section{References}

[1] Usiki A., Kojima Y., Kawasumi M., Okada A., Fukushima Y., Kurauchi T., Kamigait, O.: Synthesis of nylon 6 clay hybrid. Journal of Materials Research, 8, 1179-1184 (1993). 
[2] Wang M. S., Pinnavaia T. J.: Clay-polymer nanocomposites formed from acidic derivatives of montmorillonite and an epoxy resin. Chemistry of Materials, $\mathbf{6}$, 468-474 (1994).

[3] Lan T., Pinnavaia T. J.: Clay-reinforced epoxy nanocomposites. Chemistry of Materials, 6, 2216-2219 (1994).

[4] Balabanovich A. I., Hornung A., Merz D., Seifert H.: The effect of a curing agent on the thermal degradation of fire retardant brominated epoxy resins. Polymer Degradation and Stability, 85, 713-723 (2004).

[5] Zanetti M., Lomakin L. S., Camino G.: Polymer layered silicate nanocomposites. Macromolecular Materials and Engineering, 279, 1-9 (2000).

[6] Zilg C., Thomann R., Finter J., Mülhaupt R.: The influence of silicate modification and compatibilizers on mechanical properties and morphology of anhydride-cured epoxy nanocomposites. Macromolecular Materials and Engineering, 280, 41-46 (2000).

[7] Shah A. P., Gupta R. K., Gangarao H. V. S., Powell C. E.: Moisture diffusion through vinyl ester nanocomposites made with montmorillonite clay. Polymer Engineering and Science, 42, 1852-1863 (2002).

[8] Kim J-K., Hu C., Woo R. S, Sham M-L.: Moisture barrier characteristics of organoclay-epoxy nanocomposites. Composites Science and Technology, 65, 805-813 (2005).

[9] Rana H. T., Gupta R. K., GangaRao H. V. S., Sridhar L. N.: Measurement of moisture diffusivity through layered-silicate nanocomposites, AICHE Journal, 51, 3249-3256 (2005).
[10] GangaRao H. V. S., Craigo C.: Fiber-reinforced composite bridge decks in the USA. IABSE Structural Engineering International, 9, 286-288 (1999).

[11] Kshirsagar S., Lopez-Anido R. A., Gupta R. K.: Environmental aging of fiber-reinforced polymer-wrapped concrete cylinders. ACI Materials Journal, 97, 703715 (2000).

[12] Becker O., Cheng Y-B., Varley R. J., Simon G P.: Layered silicate nanocomposites based on various high-functionality epoxy resins: the influence of cure temperature on morphology, mechanical properties, and free volume. Macromolecules, 36, 1616-1625 (2003)

[13] Ono S., Tsuda K., Kubouchi M., Nishiyama T., Hojo H.: Degradation behavior of amine cured epoxy resin and FRP in acid solutions. in 'Proceeding of the Tenth International Conference on composite materials, Whistler, Canada' Vol.4, 215-222 (1995).

[14] Tsuda K., Kubouchi M.: Decomposition of polymeric materials. Corrosion Engineering, 44, 141-154 (1995).

[15] Massam J., Pinnavaia T. J.: Nanostructured powders and their industrial applications. Material Research Society Symposia Proceedings, 520, 223-232 (1998).

[16] Powell C. E., Beall G. W.: Physical properties of polymer/clay nanocomposites. Current Opinion in Solid State and Materials Science, 10, 73-80 (2006).

[17] Mohan T. P., Kumar M. R., Velmurugan R.: Mechanical and barrier properties of epoxy polymer filled with nanolayered silicate clay particles, Journal of Materials Science, 41, 2929-2937 (2006). 